\title{
The Effect of an Educational Computer Game for the Achievement of Factual and Simple Conceptual Knowledge Acquisition
}

\author{
Luis C. Almeida \\ Applied Media and Simulation Games Center, Indiana University of Pennsylvania (IUP), 130 Stouffer Building, \\ Indiana, PA 15705, USA \\ Correspondence should be addressed to Luis C. Almeida, luis.almeida@iup.edu
}

Received 10 July 2012; Revised 20 September 2012; Accepted 7 November 2012

Academic Editor: Hui-Chun Chu

Copyright () 2012 Luis C. Almeida. This is an open access article distributed under the Creative Commons Attribution License, which permits unrestricted use, distribution, and reproduction in any medium, provided the original work is properly cited.

This paper presents findings of a quantitative investigation of how games affect achievement of an educational objective based on the foundations of information processing. The results suggest that games can be used to assist achievement of classroom content. The results of this experimental quantitative study pointed to the overwhelming evidence that games outperformed the control group (nongames) in the achievement of factual knowledge in a group of freshman education students at a medium-size university.

\section{Introduction}

Games are part of our contemporary culture. Social science scholars have agreed that games are not a new phenomenon [1] and that the diffusion of games to the masses was a result of initiatives conducted by the Department of Defense to simulate political military crises, for example, Polish nationalistic uprising, Cold War, and the pro-Castro movement in the early 80 s $[2,3]$. Today, games are more than military strategy tools. They are an element of culture.

Since their adoption, however, video games have both fascinated and produced fear among the public at large. Part of this fear has been attributed to Reagan's remarks tying video games to the Cold War. In the same era, U.S Surgeon General, Everett Koop, stated that games were among the highest health risks in America [4].

In the 20th century, fear of games was a widespread phenomenon, especially because of its connection to violence [5]. In the 21st century, video games are now a widespread phenomenon throughout several generations of Americans [6], despite the comments made by politicians and government officials in the early 80s. Even though the first generation video games had adults as its main target audience, games are no longer exclusive to adults [7]. In America today, close to 145 million individuals play games [6] and half of the entire video game market is composed of children under the age of 12 [8]. Although we do not know the precise number of children who are game players in the United States, it seems reasonable to accept that a fair amount exists.

According to Cartstens and Beck [9], 75\% of corporate managers under the age of 34 play games and employees ages 34 or older have game experience. These findings might be the reason why DELL, HP, and Apple include games as part of their operating systems. Games are so popular today that more people buy games than movies [9].

Games have changed our society due to their impact on our economy [9]. In the United States alone, gaming is a growing billion dollar industry. However, research about the effects of games has been quite limited. Several social science researchers [10] have called for more vigorous research involving games, due to its increasing popularity. I agree that more research in games in general is necessary. I argue, however, that more research on the impact of games on learning is more pressing.

\section{Popularity of Games: Sudden Shift in Computer Game Markets}

Even though the first generation video games had adults as its main target audience, games are no longer exclusive to adults [7]. With the introduction of Atari in the 70s and 
80s and Nintendo and Sega in the 80s and 90s, the game market became focused on children. The main reason for such a shift was because the teenagers of the 70 s and 80 s were looking at more mature content in game playing [11]. In the early 1990s Nintendo targeted this market by introducing the Mario series, an approach that revolutionized the industry because games looked more cartoon-like and not as violent. This was quite appealing to children and as importantly, was not intimidating for parents. The market became children oriented and parent supported [11]. Nintendo in the 1990s was the Disney of the gaming world [11]. In addition to its shift in market emphasis, Nintendo published Nintendo Power, which in the 90s became the biggest selling kid's magazine in the world.

Because of the Mario series and the Nintendo Power magazine, Nintendo became a part of a child's culture beyond games [12]. What was an activity of adults became an activity for children. According to ESA (2010) over 70\% of American homes play computer or video games, the average gamer is 37 years old and has been playing games for over a decade. Almost $30 \%$ of gamers are over the age of 50 . Computer games now are not a "kid" thing or a "geek" thing but an "everybody" thing. Because of these recent findings, it seems reasonable to argue that perhaps, we should be using computer games more often to assist children with motivation and as a requisite of lower-level skills. By motivating students via computer game's lower-level skills tasks, we could eventually use this strategy to foster higher-order thinking skills in the future.

\section{Games and Learning}

Games have been used in educational endeavors for at least a decade. There are a multitude of studies involving games for educational purposes. A large number of scholars have made theoretical remarks about games and learning. Rieber [13] has argued that digital games assist pupils in productive play and learning though simply building microworlds and playing games. Prensky [14] went further to state that developing educational games is a moral imperative because millenniums are slow to respond to traditional Socratic methods. Gee [15] has argued that video games incorporate good learning principles supported by cognitive sciences and that assists with the "cycle of expertise" [16].

In a recent study, Sicart [17] argues that video games are well suited to teaching virtue ethics. In Sicart [17], virtue ethics is player-centric and players should learn as active recipients of game content. In an older study, Sicart argues that "Playing is an act of judgment of the rule systems and the fictional world the player is presented with (2005, p. 16). " Therefore, game play assists with being able to judge systems. Kolson [18] went further to state that the game SimCity "teaches" the learner that politics, ethnicity, and race are not major variables that impact urban planning. Barab, Thomas, Dodge, Newell, and Squire, (in preparation) argued in their SimCity 2000 at Boys and Girls Clubs study that students learn supply and demand relationships and taxation and its association to population growth by simply playing the game.
Most of the criticism involving games is related to violence. Gentile and Anderson [19] argue that violent video games are a factor in children's aggressive behavior because repetitive tasks tend to reinforce learning patterns. According to Bushman and Anderson [20], children who had prior video game experience had higher levels of aggression than those who had not. Not all studies involving games had positive results [21]. Very few scholars would disagree with this statement.

There have been too many theoretical studies concluding that games are well suited for teaching. A large amount of studies have been conducted arguing that games "teach" students to "learn" concepts while playing and connections are made just by playing a game $[18,22]$. Scholars on the negative side of the spectrum argue that games are not good because they promote violence and reinforce negative patterns. Scholars have conducted a large number of studies examining games and violence but empirical research on games and learning is scarce. Pragmatic studies of this kind are rarely conducted $[1,23]$. A possible reason for it is because educational game research shifts the importance to education rather than entertainment. The purpose of this study is to investigate if classroom games help freshman state college students majoring in education to score higher in factual knowledge exams.

\section{Research Design}

Sixty-Five Indiana University of Pennsylvania undergraduate students majoring in education were randomly assigned to the control and treatment groups. The subjects had little knowledge about the content presented in this research study prior to taking the quizzes. The students received extra points for participating in the research study. A $1 \times 1$ factorial posttest only control design was used in this experimental quantitative research study. The study included one independent variable and one dependent variable. The independent variable was the game. The dependent variable was achievement of factual knowledge. The researcher used a $t$-test to calculate the results of this research study as well as descriptive statistics. The alpha level was 0.05 . Each group had to read a script containing content about computer architecture. The control group read the script about the content then took the quiz. The treatment group read the script, played the game, then took the quiz. A posttest only design was used to reduce threats to external validity. The script was identical for both groups. There were 32 subjects in the control group and 33 in the treatment group. The experiment took place at one computer laboratory at Indiana University of Pennsylvania. Students had to log-in to the Moodle site, read the script, play the game if in the treatment group, and take a 20-question factual knowledge quiz. There were minimal disturbances during the experiment. There was one null hypothesis in this research study. $H_{0}$ : there will be no significant difference between the control group and the treatment group.

The researcher designed the game questions using the Bravo Spin off Game Engine. The graphics and program 


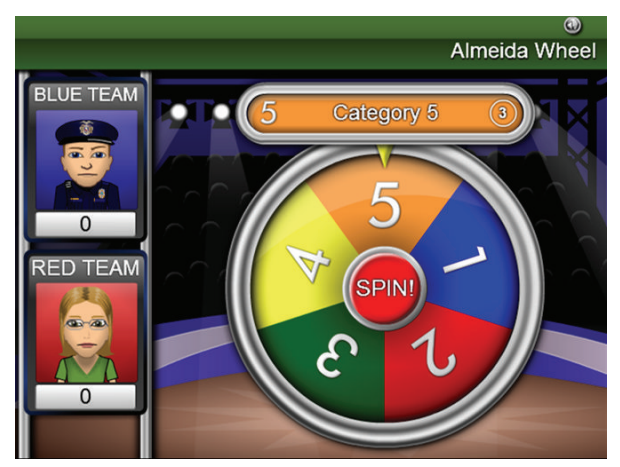

FIGURE 1: A sample game screen.

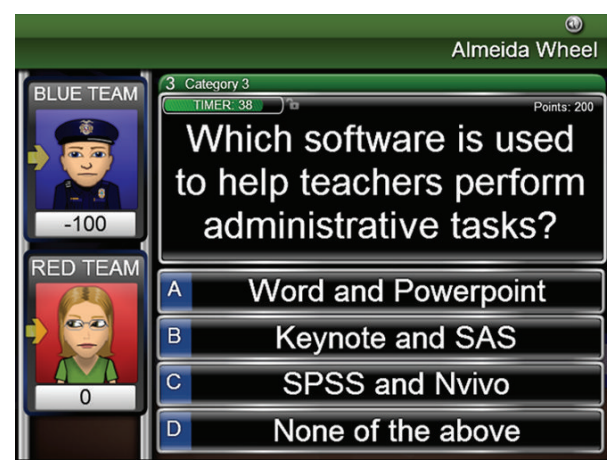

Figure 2: A sample game question.

functionalities were developed by C3Softworks, Incorporated, as shown in Figure 1. Each item answered correctly, resulted in subjects "winning" money. Each question answered incorrectly, subjects "lost" money. Figure 2 is an example of how the game looked.

\section{Results}

The researcher ran a $t$-test in order to compare the mean scores of all three tests of the control and treatment group. The alpha level was set to $0.5(P=0.05)$. Table 1 presents descriptive statistical results from this research study. Means and standard deviations are presented. The researcher predicted that students who received game treatment would outperform the control group by a letter grade.

The control group overall mean test scores was 76.8 . The games treatment group overall mean score was 83.5, which was significantly higher than the control group with no games. The researcher also found additional interesting findings beyond descriptive statistics. The number of " $\mathrm{A}$ " grades (grade $=90 \%$ or higher) in the control group was a little over $7 \%$. Please refer to Figure 3.

Based on a bell curve distribution, the results presented above are not atypical because $68 \%$ of the population is assumed to be average and only $2 \%$ are two standard deviation for the mean or "A" students. Perhaps, a 7\% "A" grade result overall might be based on student high SAT scores, quality of teaching, or class content. When subjects received a game treatment, $1 / 3$ of the students scored an " $\mathrm{A}$ " grade on
TABle 1: Descriptive statistics showing the means of factual knowledge of both the control group and treatment.

\begin{tabular}{lcccc}
\hline & Group & Mean & $\begin{array}{c}\text { Std. } \\
\text { Deviation }\end{array}$ & N \\
\hline Factual & Control (No Games) & 76.8 & 0.115 & 32 \\
knowledge & Treatment (Games) & 83.5 & 0.096 & 33 \\
\hline
\end{tabular}

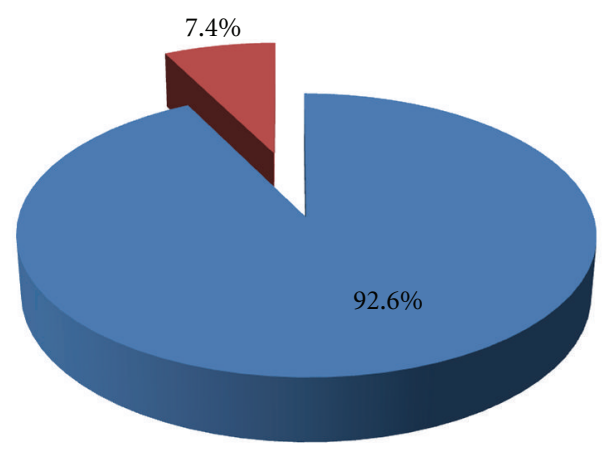

Below A

Figure 3: Control group “A” score percentages.

the test. The number of " $\mathrm{A}$ " grades in the treatment group was 33\%. Please refer to Figure 4.

This finding is exciting because the large number of " $\mathrm{A}$ " grades represents a significant difference against the control group. In addition to the difference in overall means, the treatment group overscored the control group by nearly $27 \%$.

The difference between the control and treatment groups was smaller when compared against grades over a B (0.80). The control group gained 21 points versus 5 from the treatment group, which led to believe that games assist subjects to score the highest in factual knowledge tests. Please refer to Figures 5 and 6.

In order to test the null hypothesis, the researcher conducted $t$-test. The variance in observational data was due to a random selection of a data set with less student participation. A two-sample $t$-test assuming unequal variances was conducted to account for the differences. The null hypothesis was rejected. Please refer to Table 2.

The results of the $t$-test (please refer to Table 2) indicate significant differences in factual knowledge when using games as a treatment at the $P=0.05$ level. Although there was a discrepancy of nine observations between the control group and the treatment, both had a sample of over thirty students on average per test or higher, which should be statistically sufficient for addressing issues of generalization.

\section{Conclusion}

This research found that there were significant differences among students in factual knowledge, with games as treatment. This study concurs with Almeida [1] post hoc results and Sicart [17] that when games are used against the control 


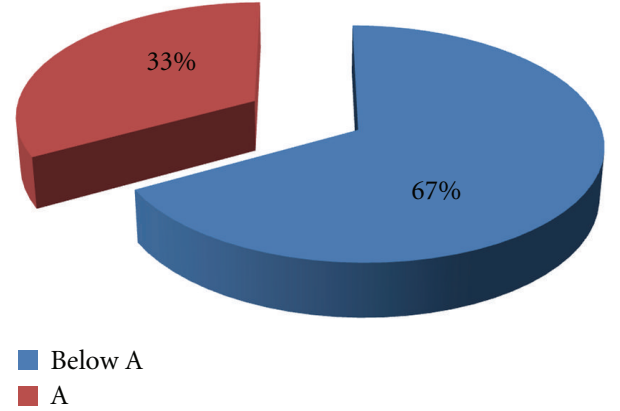

Figure 4: Treatment “A” score percentages.

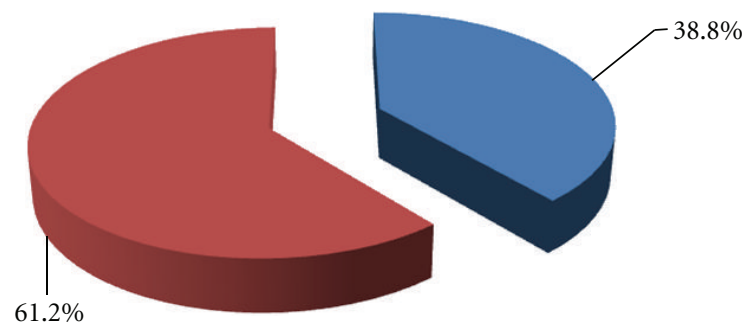

Below B

B or A

Figure 5: Control group mean scores of grades above “B.”

TABLE 2: T-Test: Two-sample assuming unequal variances.

\begin{tabular}{lcc}
\hline & Treatment & Control group \\
\hline Mean & 0.835679612 & 0.768681319 \\
Variance & 0.009150024 & 0.013258242 \\
Observations & 33 & 32 \\
Hypothesized mean difference & 0 & \\
$\mathrm{df}$ & 176 & \\
$t$ Stat & 4.374862419 & \\
$P(T \leq t)$ one-tail & 0.005 & \\
$t$ Critical one-tail & 1.653557436 & \\
$P(T \leq t)$ two-tail & 0.005 & \\
$t$ Critical two-tail & 1.973534347 & \\
\hline
\end{tabular}

group, significant increases in factual knowledge occur. It opposed the findings of Cameron [23] since the treatment did outperform the control group. Based on the results of this research study, using educational games seems to be an effective way to design instruction for factual knowledge. The overall result of this study advances the findings proposed by Hwang et al. [24], where they found that personalized education game approaches promoted learning but also motivation as the subjects of this study advanced learning acquisition.

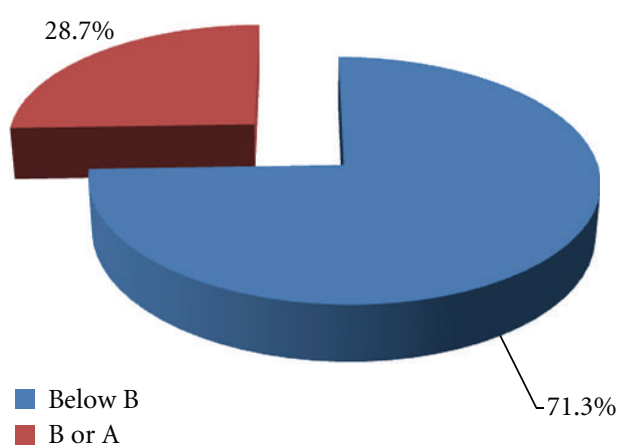

Figure 6: Treatment group mean scores of grades above "B."

\section{Limitations/Further Research}

Although this study statistically confirmed that subjects score higher on tests when game treatments are presented, there are several reasons to believe that the results of this research study could be wrong. Subjects took tests through the semester. Fatigue and class time could have influenced the results of this study. Subjects were randomly assigned among a wider body population, but it only represented a small percentage of the population which could have had an impact in the results of this study. Changes in these conditions could have resulted in different results. This study involved state college subjects majoring in education in an east coast public university. Perhaps, conducting this study in a west coast private college testing conceptual knowledge could generate results that extend the results of this study. Further studies are strongly recommended.

\section{References}

[1] L. Almeida, The phenomenological exploration of user-design in rural gifted high school students when designing a game [doctoral dissertation], Penn State University, 2008.

[2] M. E. Gredler, "Games and simulations and their relationship to learning," in Handbook of Research For Educational Communications and Technology, D. H. Jonassen, Ed., pp. 571-581, Lawrence Erlbaum, Mahwah, NJ, USA, 2nd edition, 2002.

[3] T. B. Allen, War Games, Mcgraw-Hill, New York, NY, USA, 1987.

[4] K. Squire, "Cultural framing of computer/video games," Game Studies, vol. 2, no. 1, pp. 1-13, 2002.

[5] D. A. Gentile, P. J. Lynch, J. R. Linder, and D. A. Walsh, "The effects of violent video game habits on adolescent hostility, aggressive behaviors, and school performance," Journal of Adolescence, vol. 27, no. 1, pp. 5-22, 2004.

[6] Entertainment Software association, Essential facts about the computer and video game industry, 2004, http://www.esa .com.

[7] J. Hooker, "Video games are no longer child's play," Infosynchworld, pp. 1-2, 2007.

[8] N. Breckon, NPD: Nintendo sells over 10 million Wiis in US, new lifetime sales figures for each console, 2008, http://www .shacknews.com/onearticle.x/56788.

[9] A. Cartstens and J. Beck, "Get ready for the gamer generation," TechTrends, vol. 49, no. 3, pp. 22-25, 2005. 
[10] J. Freedman, "Evaluating the research on violent video games," in Proceedings at the Culture Policy Conference, Chicago, Ill, USA, 2001.

[11] D. Deal, "A brief history of community and digital games," 2007 http://www.daviddeal.info/historyofdigitalgames/consolewars.htm.

[12] S. L. Kent, The Ultimate History of Video Games: From Pong To Pokémon and Beyond-The Story That Touched Our Lives and Changed the World, Prima, Roseville, Calif, USA, 1st edition, 2001.

[13] L. P. Rieber, "Seriously considering play: designing interactive learning environments based on the blending of microworlds, simulations, and games," Educational Technology Research and Development, vol. 44, no. 2, pp. 43-58, 1996.

[14] M. Prensky, "Digital game-based learning," ACM Computers in Entertainment, vol. 1, no. 1, p. 21, 2003.

[15] P. Gee, What Video Games Have to Teach Us About Learning and Literacy, Palgrave MacMillan, New York, NY, USA, 2003.

[16] C. Bereiter and M. Scardamalia, Surpassing Ourselves: An Inquiry Into the Nature and Implications of Expertise, Open Court, La Salle, Ill, USA, 1993.

[17] M. Sicart, The Ethics of Computer Games, The MIT press, Boston, Mass, USA, 2009.

[18] K. Kolson, "The politics of SimCity," Political Science and Politics, vol. 29, no. 1, pp. 43-46, 1996.

[19] D. A. Gentile and C. A. Anderson, "Violent video games: the newest media violence hazard," in Media Violence and Children, D. A. Gentile, Ed., Praeger, Westport, Conn, USA, 2003.

[20] B. J. Bushman and C. A. Anderson, "Violent video games and hostile expectations: a test of the general aggression model," Personality and Social Psychology Bulletin, vol. 28, no. 12, pp. 1679-1686, 2002.

[21] A. Clegg, "Games and simulations in social studies education," in Handbook of Research on Social Studies Teaching and Learning, J. P. Shaver, Ed., pp. 523-528, MacMillan, New York, NY, USA, 1991.

[22] S. A. Barab, M. Gresalfi, and A. Arici, "Transformational play: why educators should care about: games," Educational Leadership, vol. 67, no. 1, pp. 76-80, 2009.

[23] B. Cameron, The effect of online gaming, cognition and feedback type in facilitating delayed achievement of different learning objectives [doctoral dissertation], Penn State University, 2004.

[24] G. J. Hwang, P. H. Wu, and C. C. Chen, "An online game approach for improving students' learning performance in web-based problem-solving activities," Computers \& Education, vol. 59, no. 4, pp. 1246-1256, 2012. 


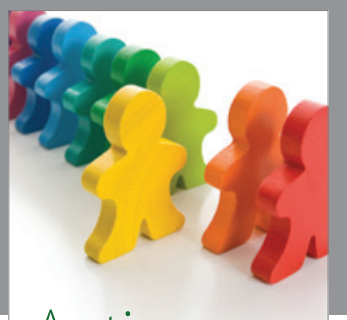

Autism

Research and Treatment
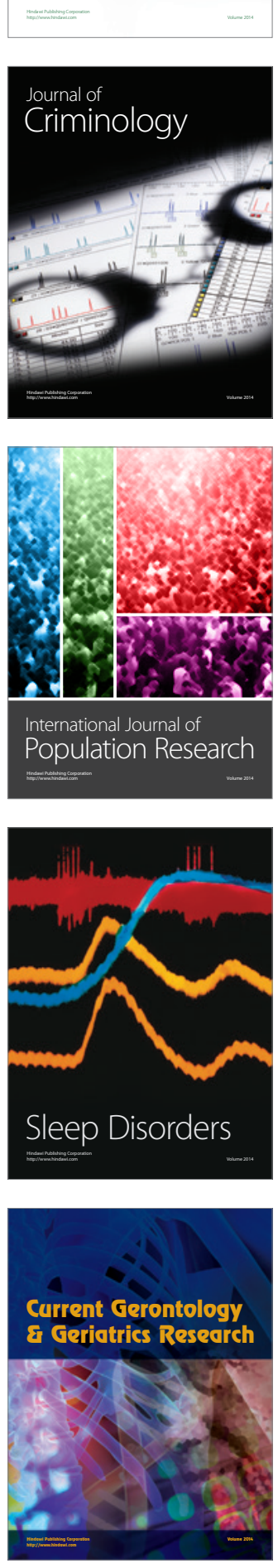
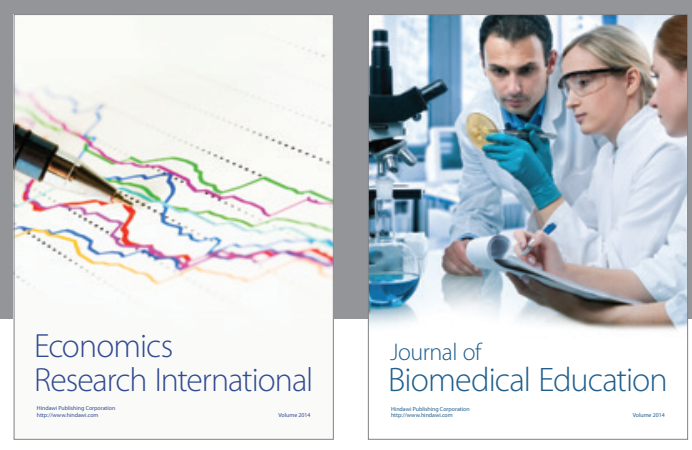

Journal of

Biomedical Education

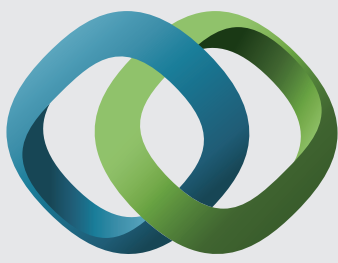

\section{Hindawi}

Submit your manuscripts at

http://www.hindawi.com
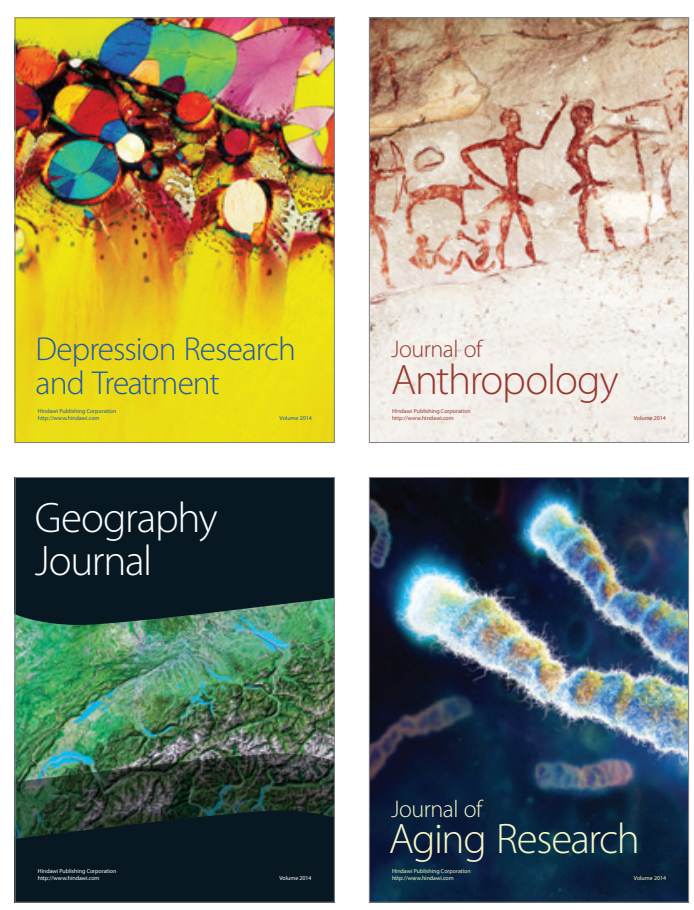

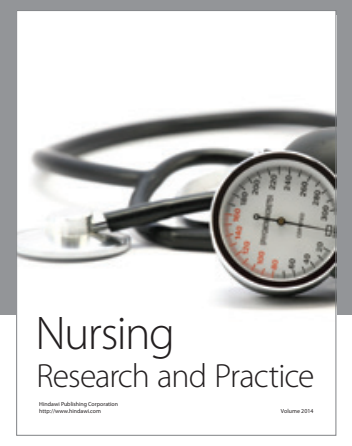

Nursing

Research and Practice

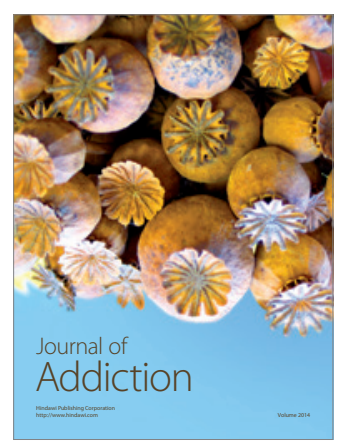

Child Development

Research

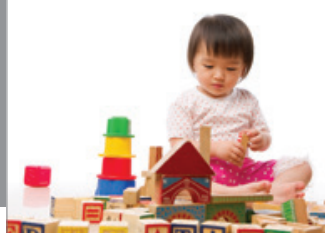

迥
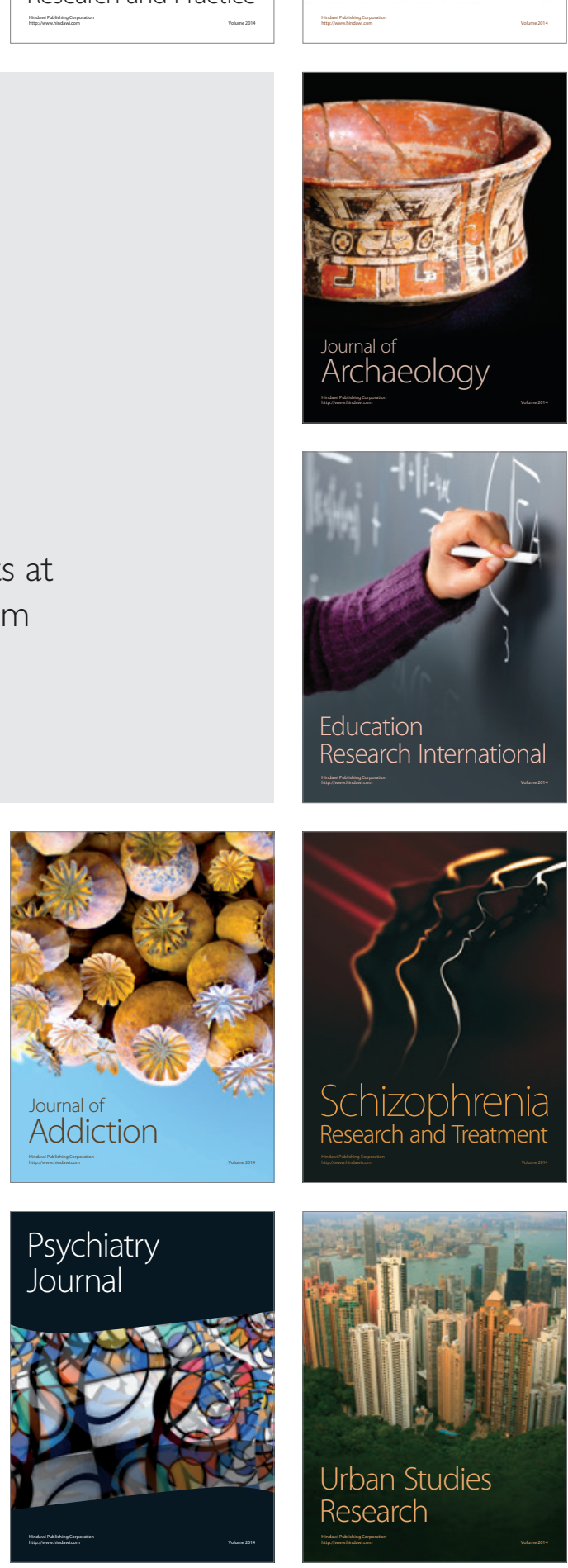